\title{
Twenty years from the foundation of the International Academy of Cardiovascular Sciences
}

\author{
Bohuslav Ostadal MD DrSc
}

$\mathrm{T}$ he International Academy of Cardiovascular Sciences (IACS) was founded in 1996 on a proposal by professor Naranjan Dhalla, and it was headquartered in the home city of its founder, Winnipeg, Manitoba. Established by renowned cardiologists, both experimental and clinical, the Academy provides the organizational structure for the worldwide sharing of research and education in the field of heart health. The importance of such an effort is strongly supported by the fact that cardiovascular diseases represent the number one killer, with a mortality rate exceeding $50 \%$ of total mortality. The Academy believes that the effective collaboration of experimental and clinical cardiologists will improve this unfavourable situation.

One can ask whether the world of cardiology needs another international society. I am deeply convinced that the only answer is yes and I take this opportunity to briefly explain my arguments. I am old enough to have been able to follow the development of the international cardiology community - particularly the relationships between clinical and experimental cardiologists - from the early 1960s of the past century. In 1964, the European Congress of Cardiology was organized in Prague, former Czechoslovakia. From the total number of accepted presentations, only three were devoted to experimental cardiology. This fact stimulated congress participants Richard Bing, the father of cardiac metabolism, Eors Bajusz, a brilliant HungarianAmerican biologist, and my teacher Otakar Poupa to undertake the steps to improve this situation. Their highly enthusiastic effort to promote basic cardiology led finally to the foundation of the International Study Group for Research in Cardiac Metabolism in Dubrovnik, former Yugoslavia, in 1968. The name was later - at the suggestion of Naranjan Dhalla, one of its founders - changed to the International Society for Heart Research. Unfortunately, during further development, the thinking and philosophy of experimental and clinical cardiologists became very divergent. The problems were, of course, on both sides: extreme concentration on evidence-based medicine among clinical cardiologists; and massive orientation toward molecular biology among experimental cardiologists. This development led officials of the American and European Cardiology Societies to the introduction of basic research sessions into the regular scientific program of their congresses. This laudable step was an important contribution to improved understanding between both communities. The disadvantage, however, is the size of the main congresses, which often exceeds 20,000 participants and, thus, complicates communication between clinical and experimental cardiologists. It is here that I see a role for the activities of the Academy. It is more than clear that only close collaboration between clinical and experimental cardiologists can be the driving force in the progress of contemporary cardiology. A more intimate and friendly atmosphere at IACS meetings thus, should create the productive background for effective discussion.

And now, a few words about the name of the Society. The English term 'Academy' is derived from ancient Greek 'Academia', a grove of trees and gymnasium outside of Athens where Plato taught. The word relates to the name of the supposed former owner of that estate, the Attic hero Akademos. According to the Webster dictionary, 'Academia' continues to provide scientific education and research. Alternatively, it means the life, community or world of teachers, schools and education.

With this definition, the main goal of IACS is, therefore, the continuous education of the cardiology community, with the aim of understanding the pathogenesis, diagnosis and therapy of cardiovascular disease worldwide. The working conferences are oriented predominantly toward young researchers and, since 1996, IACS has organized or participated in a total of 125 meetings. In addition, IACS recognizes the achievements of cardiovascular investigators by Fellowship in the Academy. Today, IACS has 242 regular Fellows and 59 Emeritus Fellows. Furthermore, IACS honours extraordinary individuals with Medals of Merit. This highest honour of the Academy is bestowed for outstanding achievements in cardiovascular education and research once per year. Among the 31 awardees are Nobel Prize winners RF Furchgott, Sir J Vane, LJ Ignarro and F Murad. Information about the life of the scientific society is an important aspect of the effective function of the Academy. IACS publishes the official bulletin CV Network, and the official Journal of the Academy became Current Research: Cardiology, published by Pulsus Group (Oakville, Ontario).

In conclusion, IACS continues to demonstrate its viability, scientific tact, enthusiasm and utility. I am convinced that it has earned its strong position in the cardiology community and, thus, fulfills the vision of its founder, professor Dhalla. On behalf of all members and friends of IACS, I express our sincere thanks for everything he has done for the Academy. Simultaneously, we wish him all the best in his important life anniversary. Ad multos annos !

Institute of Physiology, Czech Academy of Sciences, Prague, Czech Republic Correspondence: Dr Bohuslav Ostadal, Institute of Physiology, Czech Academy of Sciences, Prague, Czech Republic. E-mail bohuslav.ostadal@fgu.cas.cz 